\title{
HYPER SPECTRAL REMOTE SENSING FOR DAMAGE DETECTION AND CLASSIFICATION MODELS IN AGRICULTURE - A REVIEW

\author{
Akshay Dhande ${ }^{1}$, Rahul Malik ${ }^{2}$
}

\author{
Department of Electronics and Telecommunication Engineering, Lovely Professional University, Punjab, India \\ Department of Computer Science and Engineering, Lovely Professional University, Punjab, India \\ akshaydhande126@gmail.com
}

\begin{abstract}
Agriculture is the pillar of the financial system of any country and it's far enormously crucial for financial improvement and social stability. Remote sensing has numerous benefits within the discipline of agronomical studies purpose. Remote sensing has the capacity to face this big obstacle in the evolutionary changes in agricultural practices, by delivering recurrent information on crop condition at multiple scales and for different actors during the season. Because of the rapid changes in farming started from mid to past 1980, remote sensing has become an indispensable a part of precision agriculture. Agricultural systems need to be monitored in regular interval. Remote sensing act as vital method in well timed tracking and provides a correct snapshot of the agricultural with good accuracy. The tracking of agricultural strongly follows seasonal patterns on the subject of the organic life of crops. Because of this background we studied various remote sensing methods like crop classification, crop tracking and yield assessment. We discovered that almost all of the remote sensing methods have been exploratory investigations, examined on a nearby scale with direct dependence on ground data. In tandem with other specialized methods such as geographical information systems and global positioning systems, remote sensing plays an important role in the measurement and monitoring of agricultural activities. We begin this review by presenting an outline of the existing methods of remote sensing relevant to the agricultural sector. This paper analyses remote sensing methods progress, problems and future in agricultural context. This article will offer an outline of commercially remote sensors having high resolution which have been used or have ability for accuracy in collecting agriculture information. Further, overview illustrates current research trends in remote sensing methods that allow reinforcing applicative skills with precise necessities for specific forms of stakeholders. We offer a synthesis of the rising possibilities in remote sensing techniques that have to
\end{abstract}

reinforce the role in imparting long time and efficient services for agricultural purpose. SAR remote sensing techniques have extremely good capability and could play an important role in diverse fields of agricultural remote sensing. Finally, the paper outlines challenges, limitation and future trends of remote sensing methods in crop evaluation. This paper concludes that current utilization of remote sensing methods in crop evaluation still remains in an experimental stage.

\section{Introduction}

Remote sensing is the capacity to collect data from an entity or event in isolation. Remote sensing in addition to ground measurements with greater precision and correctness is a method for tracking the earth's properties using space technology. This requires a platform mounted sensor or instrument, such as an aircraft, satellite, probe or a UAV. Utilization of electromagnetic spectrum (infrared, visible and microwaves) is the basic principle behind remote sensing for examination of the earth's features. Figure 1 shown the typical target responses to these wavelength regions which are distinct for water, soil, vegetation, so they are used to discriminate between soil, vegetation, water and other related characteristics. Usually, the sensor tests the electromagnetic radiation that the target under observation either reflects or produces. Based on the basic characteristics of the instrument and the platform of instrument, the different type of information is available from remote sensing. These properties are motion plan for UAV, satellite orbitography, direction and location of the field sensor, passive or active sensing, and characteristics of the optical lens and detector array and storage capability. The directional, polarization, strengths of spectral, spatial resolution and re-visit frequencies, also the ratio of signal to noise are describe by the characteristics of the sensor and its platform. The atmospheric conditions and illumination indirectly influence data acquisition. 


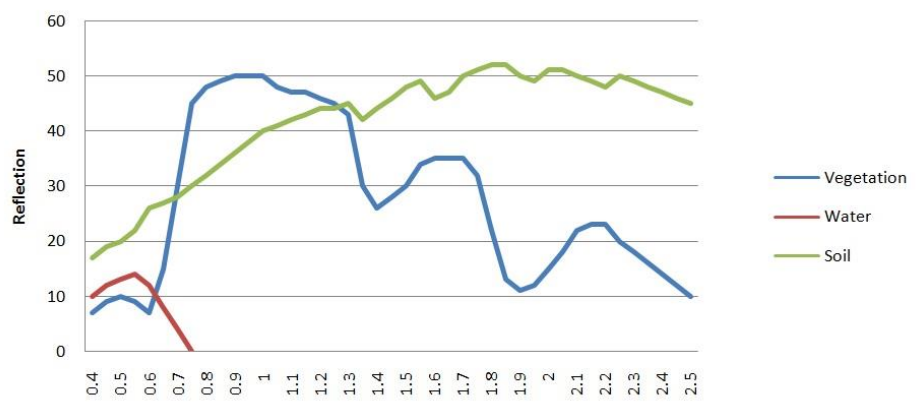

Figure 1 Reflectance curves of different spectrum for water, dry bare soil and vegetation

In view of this demanding agricultural context, there is a clear need to track crop development, environmental contexts and status in different site, for various purposes with different temporal resolutions. Remote sensing for farming surveillance is a huge topic that has been commonly discussed from different points of view, often focused on particular applications (yield estimation, precise farming, irrigation), with particular remote sensing platforms (Synthetic Aperture Radar SAR, Satellites, Unmanned Ground Vehicles-UGV, Unmanned Aerial Vehicles-UAV) or on sensors or particular site and climatic circumstance (continent or country, dry lands or wetlands). Financial returns are motivated by high pressure to forecast short-term yields on a national, regional and agricultural scale. As remote sensing provides a non destructive means of routinely supplying repetitive data from the regional to the worldwide scale it tends to be an important method for reacting to the above criteria. Remote sensing data will significantly contribute to tracking the surface characteristics of the earth by providing cost-effective, synoptic, timely, and repetitive knowledge about the surface of the earth. (Justice et al. 2002). Remote sensing inputs fused with crop simulation models are extremely helpful in crop yield prediction. Reliable and well-timed crop mapping, planting area data and production progress monitoring are the demands of sound agricultural management and policy making. The crop growth status acquired by remote sensing may provide a guide for developing agricultural product regulation and control policies. As befouls will become a big source of energy (Demirbas 2009), this adaptation is also likely to be heavily motivated by the energy transition, although farming operations may have to be shifted in order to optimize production costs and transport. Biomass, plant water content, Leaf area index ( LAI), chlorophyll quality features are used to form a relationships with eco-physiological and bio-physical parameters of the crop, which are characterized by the optical remote sensing techniques for analyzing and tracking crop growth status and yield. The growing amount of published literature, as seen in Figure 2 since 2010, has shown that remote sensing of agricultural applications has now become a new field of study. By studying the work done by the researcher we seek to supplement past efforts. We have not focus on detailed distinctions in this analysis between approaches or outcomes, nor do we have recommended any one best way to use remote sensing for agriculture. Rather, the aim of this review is to give a detailed summary of remote sensing techniques for agricultural, while doing so we have, redirecting readers to more relevant reviews or articles by referencing the key sources and ideally the latest ones.

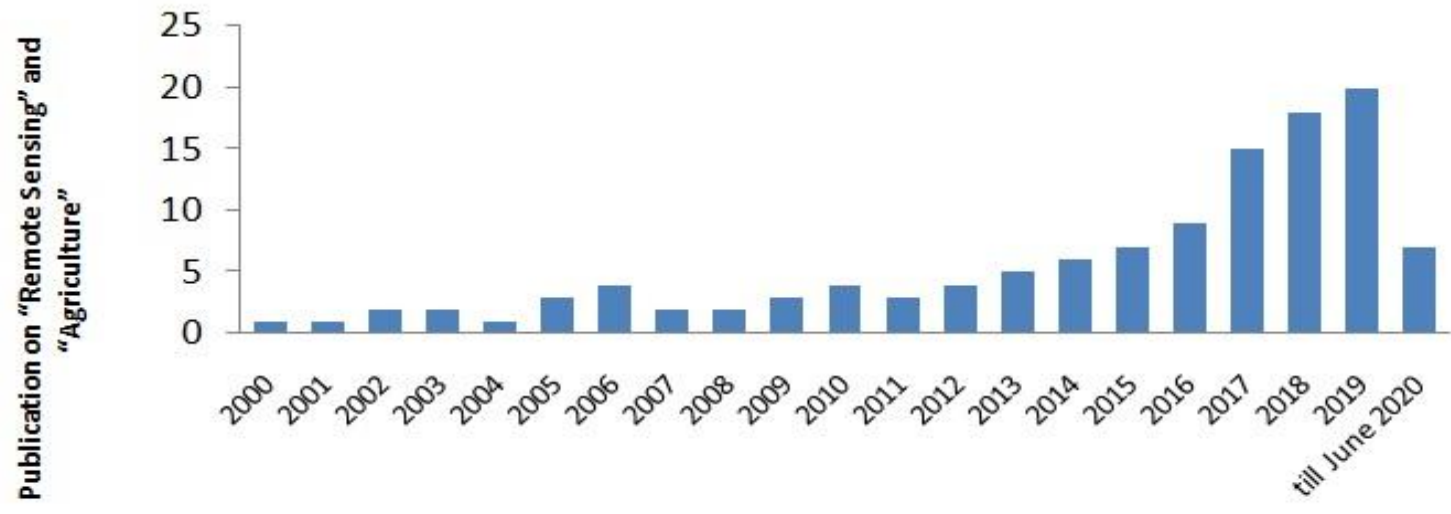

Year

Figure 2 Number of publications in the Web of Science database covering the subject of Agriculture and Remote Sensing from 2000 to 2020

This paper is broken down into three important parts. A description of existing remote sensing techniques that are applicable to agricultural backgrounds is given in the first part of this paper. It identifies the plant characteristics and agronomic variables that can be calculated by remote sensing and describes the analytical or deterministic approaches to recovering them. We focused on how remote sensing aims to address the unique needs of main agricultural applications for multiple stakeholders in the second section of this 
review. At last, we suggested a synthesis of the evolving potential that enhances the role of remote sensing in providing agricultural applications with productive, long-term services and effective.

\section{Agriculture Applications of Remote Sensing}

The primary aim of farmers in precise farming is to ensuring that food production to feeds a increasing population conducting, to conduct commercially sustainable practices, and reducing harmful environmental effects and contributing to climate improvement. Remote sensing appears to be an unavoidable tool because it is a non destructive way of monitoring vegetation spatially and temporally. These multiple implementations are connected to diverse criteria for stakeholders (e.g. Farmers, Local Authorities, or Governments) that include different temporal scales from real time to long term, and spatial scales (e.g. National, State and District) with different degrees of precision and a priori knowledge of crop condition (Table I). In terms of data collection and processes, have direct impacts on the decisions taken by remote sensing based solutions.

Table 1.

Use of remote sensing in precise farming for the various participant and at different time scale ++ stands for Real Time, \#\# is Crop life cycle, $\$ \$$ is Year and ** corresponds to decades

\begin{tabular}{|c|c|c|c|}
\hline Use of Remote sensing & Farmers & Local Authorities & Governments \\
\hline Crop Classification & -- & ++ & $\$ \$, * *$ \\
\hline Crop Tracking &,$++ \# \#$ &,$++ \$ \$$ & $++, \# \#, \$ \$, * *$ \\
\hline Yield Assessment & $\# \#$ & $\$ \$$ & $\$ \$, * *$ \\
\hline Disaster Alert & ++ & ++ & $++, \$ \$, * *$ \\
\hline
\end{tabular}

Agricultural awareness of significance consists of the characteristics or attributes of agricultural systems and in particular, of how these systems varies in space and time. Nock et al. ( 2016) (Nock, Vogt, and Beisner 2016) identified functional traits that affect the efficiency or fitness of the organism as biochemical, morphological, structural, physiological, phonological or behavioral characteristics. Variables have been interpreted as characteristics which differ by plant, crop, and region. The type of the agronomic characteristics may be the crop type (typological), soil moisture or crop canopy temperature (physical), leaf nitrogen content (chemical), crop phonology (biological), leaf inclination (structural), or plant density (geometrical).

The initial phase of remote sensing research in agricultural applications was concerned with the use of remote sensing data for crop types and the classification of ground cover types. Research is currently focused on the characterization of the biophysical characteristics of crops. For many years, remote sensing has been used in the tracking and study of agricultural practices. Its ability to provide routine information without unharmonious to crop sampling and can be used to provide critical data for specific agricultural applications is the benefit of remote sensing. Remote sensing is a cost effective options for data collection for big territory. In India the remote sensing technique is majorly use for two agricultural application yield estimation and crop classification. Based on the biological characteristics of crops, remote sensing technology is likely to transformation the characterization and identification of agricultural output. For yield estimation, crop phonological data identification of crop disease and disruptions, remote sensing satellites may be used (Bernardes et al. 2012). Kingra et al., (Kingra, Majumder, and Singh 2016) observed that for generating basic information that can be effectively use for different fields, including urban development, drought mapping, changes in land use, identification of diseases and tracking of crop growth, together with GIS, remote sensing is very useful. Because of upcoming technology like hyper spectral sensors or narrow band and sensors mounted on satellite or aircraft with increased spatial resolution, the remote sensing methods are more beneficial. For the development of more comprehensive crop monitoring, such as the identification of crop pathogens and the identification of small pests, optical remote sensing is very helpful. The researcher has now integrated numerous types of advanced sensors that are able to provide the reliable data in the chipper manner and then conventional data collection approach on a timely basis.

\section{Classification Techniques}

Remote sensing important for the crop classification, crop acreage estimation and output assessment. Using digital image processing techniques and aerial photos, several research experiments were performed. The field of remote sensing, however, helps to increases the greater accuracy of forecasts and minimize the volume of field data to be gathered (Kingra, Majumder, and Singh 2016). When we compared to broadband multispectral remote sensing, the ability of hyper-spectral data, SAR and optical remote sensing data to significantly advance the classification of crops (Thenkabail, Lyon, and Huete. 2011). In order to define, map, model and classify and also to research the basic biochemical and biophysical quantities of the world's main agricultural crops, This was helpful in deciding the 33 ideal HNBs and an equal sum of the difference between specific two-band uniform HVIs (Thenkabail et al. 2013). Some remote sensing researchers use hyper spectral data to focus more on succinct points of view of territorial crop harvesting conditions. Other pay greater attention to physical features of the crop environment, such as water supply and crop disease, in connection with the crop condition in the evaluation of crop health and development. The Normalized Difference 
Vegetation Index is the index commonly used to measure the state of vegetation. Even though the NDVI has become the most regularly utilized vegetation index but to reduce effects of the atmosphere and soil on the spectral calculation many attempts have been made to establish more indices. There are many indexes available like Soil Adjusted
Vegetation Index, General Yield Unified Reference Index. All indices were used for drought tracking and mapping as well as assessment of the physical state and yield of vegetation. The table II shows the comparison of plant classification techniques.

Table 2.

Comparison of plant classification techniques

\begin{tabular}{|c|c|c|}
\hline Ref. & Method & Future Scope \\
\hline $\begin{array}{l}\text { (Ghazaryan } \\
\text { et al. 2018) }\end{array}$ & $\begin{array}{l}\text { Land sat-based time series metrics were pre-processed } \\
\text { and analyzed using the Google Earth Engine cloud } \\
\text { computing tool to capture phonological variation } \\
\text { within the season. classification techniques use are } \\
\text { decision fusion, vector machines, random forest } \\
\text { Accuracy in } \%=\mathbf{8 0}\end{array}$ & $\begin{array}{l}\text { The most correctly } \\
\text { classification was done by } \\
\text { winter cereals, whereas we } \\
\text { observed classification errors } \\
\text { among summer crops. }\end{array}$ \\
\hline $\begin{array}{c}\text { (Azar et al. } \\
2016)\end{array}$ & $\begin{array}{l}\text { multi-temporal data, supervised classification (EVI, } \\
\text { NDFI, RGRI) } \\
\text { Accuracy in } \%=\mathbf{8 6 . 5}\end{array}$ & Can be use for complete year. \\
\hline $\begin{array}{l}\text { (Bagheri et } \\
\text { al. 2018) }\end{array}$ & $\begin{array}{l}\text { Quadratic discriminate analysis, linear discriminate } \\
\text { analysis, soft independent class analogy modeling } \\
\text { (SIMCA), mahalanobis discriminate analysis and } \\
\text { partial least square discrimination analysis have been } \\
\text { introduced as classification techniques. }\end{array}$ & \\
\hline $\begin{array}{c}\text { (Hao et al. } \\
2016)\end{array}$ & $\begin{array}{l}\text { Two vegetation indices are derived from } \\
\text { atmospherically corrected reflectance within the red, } \\
\text { near-infrared, and blue wavebands. i. e. normalized } \\
\text { difference vegetation index (NDVI), and the enhanced } \\
\text { vegetation index (EVI) } \\
\text { Accuracy in } \%=93.28\end{array}$ & $\begin{array}{l}\text { Furthermore, by using new } \\
\text { sources of data we may } \\
\text { further develop the system of } \\
\text { this analysis and thus obtain } \\
\text { more accurate training } \\
\text { samples from crop type in } \\
\text { coming future. }\end{array}$ \\
\hline $\begin{array}{l}\text { (Kuželka and } \\
\text { Surový 2018) }\end{array}$ & $\begin{array}{l}\text { Structure from Motion technique with subsequent } \\
\text { automated classification of the automatic } \\
\text { segmentation of crop use. } \\
\text { Accuracy in } \%=\mathbf{9 9 . 3}\end{array}$ & \\
\hline $\begin{array}{l}\text { (Hütt and } \\
\text { Waldhoff } \\
\text { 2018) }\end{array}$ & $\begin{array}{l}\text { Multi-Data Approach (MDA). } \\
\text { Therefore, we extend the MDA by using Land Use / } \\
\text { Land Cover classifications derived from six multi } \\
\text { temporal and dual-polarimetric strip map images from } \\
\text { TerraSAR-X that do not require cloud-free conditions. } \\
\text { Accuracy in } \%=\mathbf{7 5}\end{array}$ & $\begin{array}{l}\text { However, classification does } \\
\text { not seem to be as reliably } \\
\text { specific for potatoes, as may } \\
\text { be seen by frequent contrasts } \\
\text { with differences in the fields } \\
\text { of training and validation. }\end{array}$ \\
\hline $\begin{array}{l}\text { (Basukala et } \\
\text { al. 2017) }\end{array}$ & $\begin{array}{l}\text { Based on random forest (RF), multiple Land sat } 8 \\
\text { images, support vector machine (SVM), robust non- } \\
\text { parametric machine learning algorithms, and a } \\
\text { common maximum likelihood parametric algorithm } \\
\text { (MLC). }\end{array}$ & -- \\
\hline
\end{tabular}

\section{Abiotic and Biotic Factors}

SAR and optical remote sensing data has become a fundamental instrument for observing and evaluating crop worry because of abiotic and biotic factors. In order to determine the cause for insect proliferation, SAR and optical remote sensing data systems should be mastered to establish strategies for preventing their spread and taking effective control steps. The remote sensing method has been used in the survey and observation of pest defoliation to relate contrasts in spectral responses to choruses, decreasing foliage and changing leaf color over a given period of time, anticipating these distinctions to be linked, coordinated and deciphered (Franklin 2001). Identifying and preparing defoliation, characterizing pattern disruptions and so on, and supplying information to the pest control system have been included in the framework of remote sensing (Lee et al. 2010). SAR and optical remote sensing data can be used for various types of vegetation indices on land-sat images taken before and after defoliation to distinguish between safe and unhealthy vegetation cover. Data from MODIS may be an effective instrument for weakened pests and the confirmation of plant indices on a plot scale. Riedell, Osborne, and Hesler (2004) (Riedell, Osborne, and Hesler 2004) reported to discover 
pest infested and diseased plants, remote sensing technology is an efficient and cheap technique. Remote sensing methods can be used to track individual insect pests and to determine the difference between insect damage and plant disease damage. They indicated that spectral reflectance contrasts and canopy characteristics between harm from disease contamination and harm from insect infestation can be measured by remote sensing in crop canopies. Mirik et al . ( 2013) (Mirik et al. 2013) concluded that explicit Wheat Streak Mosaic Ailment infection at the site can be reliably classify and quantify by using the land sat 5 TM image. Franke and Menz (2007) (Franke and Menz 2007) concluded that fungal wheat diseases can be monitor by high resolution multispectral remote sensing data. The table 3 shows Comparison of plant classification techniques.

Table 3.

Comparison of plant disease detection techniques

\begin{tabular}{|l|l|c|l|}
\hline \multicolumn{1}{|c|}{ Ref. } & \multicolumn{1}{|c|}{ Method details } & Accuracy & \multicolumn{1}{c|}{ Type of plant } \\
\hline $\begin{array}{l}\text { Qu, Qu, and } \\
\text { Wang 2009) }\end{array}$ & $\begin{array}{l}\text { Smoothing Stepwise Discriminate Analysis, } \\
\text { SPA and SFA }\end{array}$ & $93 \%$ & $\begin{array}{l}\text { Mangrove forest field canopy } \\
\text { spectra }\end{array}$ \\
\hline $\begin{array}{l}\text { (Chen, Shan, and } \\
\text { Zhao 2008) }\end{array}$ & Spectral angle dist., feature parameters & $96 \%$ & $\begin{array}{l}\text { Custom dataset from different } \\
\text { plant species }\end{array}$ \\
\hline $\begin{array}{l}\text { (Kahya, Bayram, } \\
\text { and Reis 2010) }\end{array}$ & $\begin{array}{l}\text { Smoothing, Classification and Regression } \\
\text { Tree and Stepwise Discriminate Analysis }\end{array}$ & $93 \%$ & $\begin{array}{l}\text { Mangrove forest field canopy } \\
\text { spectra }\end{array}$ \\
\hline $\begin{array}{l}\text { (Lu and Weng } \\
2007)\end{array}$ & Linear Discriminate Analysis VIP score & $88 \%$ & $\begin{array}{l}\text { Forestry species from airborne } \\
\text { imagery }\end{array}$ \\
\hline $\begin{array}{l}\text { (Tarbalka et al. } \\
2010)\end{array}$ & $\begin{array}{l}\text { Principal Component Analysis matrix with } \\
\text { band correlation }\end{array}$ & $77 \%$ & $\begin{array}{l}\text { European forest trees species } \\
\text { from airborne imagery }\end{array}$ \\
\hline $\begin{array}{l}\text { (M. Chi, } \\
\text { Fenediktsson, and } 2009)\end{array}$ & $\begin{array}{l}\text { Continuum Removed Stepwise } \\
\text { Discriminate Analysis }\end{array}$ & $\begin{array}{l}\text { Himalayan forest species from } \\
\text { satellite imagery }\end{array}$ \\
\hline $\begin{array}{l}\text { Zhang 2010) } \\
\text { Analysis of Variance, Linear Discriminate }\end{array}$ & $90 \%$ & $\begin{array}{l}\text { Mangrove species from lab leaf } \\
\text { spectra }\end{array}$ \\
\hline
\end{tabular}

\section{Prediction of Crop Yields}

The estimation of how successful a crop will be ahead of harvesting is of particular importance to different participants : international organizations and national governments to improve the availability of food to each and every individuals (Kogan, Development, and Series 2019). With change in the stakeholder, the spatial level at which the information needs to be updated. Farmers, committed in forecasting their expected economic gains from their own lands, will be based on the field or farm scale. Instead, states, multinational organizations and commodities traders are involved in collective yield forecasts at individual administrative unit's level or at state and national scales. In order to advise policymakers on trade policies, government intervention in business or emergency relief, such information is important. Farm insurers are interested at both coarse and fine levels in order to measure the possible farm productivity risks for particular fields. Crop yield, is the standard productivity metric considered in this sense. This article aims to predict crop yields over vast geographical regions. Agricultural tracking programs on a national and international level exist today with the goal of delivering up to date information about the food growth. Remote sensing is use by all the present systems as tool to indicate the crop status in real time to predict the crop output, having the particular benefit of offering explicit details of variability of agricultural environments spatially and temporally. The Earth
Observations Group initiated GEOGLAM project which enhanced the role of remote sensing in predicting crop yields (Becker-Reshef et al. 2010). Many experiments has concentrated on some other indicators to enhance yield prediction, including phonological metrics derived from the time series of vegetation indices (Bolton and Friedl 2013). We observed that fewer studies have been focused on produce quality, which is more difficult to evaluate since it is strongly reliant to genotypes. In smallholding ecosystems, which are also more likely to be affected by food shortages, the issue of small field sizes is compounded. The biggest hurdle in establishing experimental relationships is the lack of accurate data on crop yield which is becomes of the small size of farm. Estimating yield from optical remote sensing more challenging in small farms because abundant cloud coverage during the growing season (Duncan, Dash, and Atkinson 2015). High degree of temporal revision, the fine spatial resolutions, and broad geographic coverage persisted are the key restrictions in yield monitoring.

\section{Conclusion}

Use of remote sensing is really an efficient strategy for precision farming, considering the diverse existence of the variables associated with agriculture. The different applications for agricultural remote sensing were reviewed in this article, outlining the drawbacks as well as opportunities associated with some of these technologies. Detailed reviews of the existing trends were presented and also the current 
challenges and future planning strategies both are addressed and suggested in this review. We grouped remote sensing farming applications in this review into three major categories: Crop Classification, Crop Monitoring, and Yield Estimation. As last decades development in SAR cameras have become important role in imaging modes, that can provide different forms of data sources for remote sensing techniques in farming particularly in crop condition assessment, crop yield estimation, soil moisture estimation and crop type mapping. Techniques which are still devoted to the fixed depth that creates large differences across various scales between sources of data and designs because of which transferability of techniques over different scales is difficult and an ongoing research target. Comparing the optical sensors with systematic armature radar (SAR), in the field of agricultural remote sensing, SAR has particular importance because, in bad weather conditions, it can collect data. It is observed that basic remote sensing research has advanced more slowly, we can take the benefit if data available by effort in the field of deep learning and machine learning with provide the solution in real time and satisfy the operational requirement. Both internationally and national level the timeliness of the accessibility and analysis of data is important. Even on the small farms scale remote sensing is functional for identifying and handling multiple crop problems as well as for analyzing multiple pathogens in various crops, including on small farms. A district or state level application software focused on available data from different crops obtained from remote sensing and GIS approaches is a need to be establish to allow efficient use of crop information to boost the economy.

Remote sensing data will be used by policymakers (e. g. government) to make crucial decisions on the strategies they can implement to handle national agricultural problems. It can also be used as an important instrument for empowering agricultural players to participate in collective action on international problems such as climate change, soil degradation and depletion of biodiversity. Remote sensing serves to provide the multiple parties with greater accountability while preserving their sovereignty. Ultimately, it is also possible to see remote sensing as a medium for addressing questions relevant with transition within our environment.

\section{References}

Azar, Ramin et al. 2016. "Assessing In-Season Crop Classification Performance Using Satellite Data: A Test Case in Northern Italy." European Journal of Remote Sensing 49: 361-80.

Bagheri, Nikrooz, Hosna Mohamadi-Monavar, Aslan Azizi, and Abolghasem Ghasemi. 2018. "Detection of Fire Blight Disease in Pear Trees by Hyperspectral Data."
European Journal of Remote Sensing 51(1): $1-10$.

https://doi.org/10.1080/22797254.2017.1391 054.

Basukala, Amit Kumar et al. 2017. "Towards Improved Land Use Mapping of Irrigated Croplands: Performance Assessment of Different Image Classification Algorithms and Approaches." European Journal of Remote Sensing 50(1): 187-201. http://dx.doi.org/10.1080/22797254.2017.130 8235.

Becker-Reshef, Inbal et al. 2010. "Monitoring Global Croplands with Coarse Resolution Earth Observations: The Global Agriculture Monitoring (GLAM) Project." Remote Sensing 2(6): 1589-1609.

Bernardes, Tiago et al. 2012. "Monitoring Biennial Bearing Effect on Coffee Yield Using MODIS Remote Sensing Imagery." Remote Sensing 4(9): 2492-2509.

Bolton, Douglas K., and Mark A. Friedl. 2013. "Forecasting Crop Yield Using Remotely Sensed Vegetation Indices and Crop Phenology Metrics." Agricultural and Forest Meteorology 173: 74-84. http://dx.doi.org/10.1016/j.agrformet.2013.01 .007 .

Chen, S. J., D. D. Shan, and W. C. Zhao. 2008. "Examination and Investigations Ashore Spread Arrangement Strategies Utilizing Remote Detecting Information." Journal of Liaoning Technical University (Natural Science) 29(4): 567-570.

Demirbas, Ayhan. 2009. "Political, Economic and Environmental Impacts of Biofuels: A Review." Applied Energy 86(SUPPL. 1): S108-17.

http://dx.doi.org/10.1016/j.apenergy.2009.04. 036.

Duncan, John M.A., Jadunandan Dash, and Peter M. Atkinson. 2015. "The Potential of Satellite-Observed Crop Phenology to Enhance Yield Gap Assessments in Smallholder Landscapes." Frontiers in Environmental Science 3(AUG): 1-16.

Franke, Jonas, and Gunter Menz. 2007. "MultiTemporal Wheat Disease Detection by MultiSpectral Remote Sensing." Precision Agriculture 8(3): 161-72.

Franklin, Steven E. 2001. Remote Sensing for Sustainable Forest Management.

Ghazaryan, Gohar et al. 2018. "A Rule-Based Approach for Crop Identification Using Multi-Temporal and Multi-Sensor Phenological Metrics." European Journal of Remote Sensing 51(1): 511-24. https://doi.org/10.1080/22797254.2018.1455 540.

Hao, Pengyu et al. 2016. "Crop Classification Using Crop Knowledge of the Previous-Year: Case Study in Southwest Kansas, USA." European Journal of Remote Sensing 49: 
1061-77.

Hütt, Christoph, and Guido Waldhoff. 2018. "Multi-Data Approach for Crop Classification Using Multitemporal, DualPolarimetric TerraSAR-X Data, and Official Geodata." European Journal of Remote Sensing 51(1): 62-74. https://doi.org/10.1080/22797254.2017.1401 909.

Justice, C. O. et al. 2002. "An Overview of MODIS Land Data Processing and Product Status." Remote Sensing of Environment 83(1-2): 315.

Kahya, O., B. Bayram, and S. Reis. 2010. "Land Spread Characterization with a Specialist Framework Approach Utilizing Landsat ETM Symbolism: A Contextual Investigation of Trabzon",." Environmental Monitoring and Assessment 160(1): 431-438.

Kingra, P K, Debjyoti Majumder, and Som Pal Singh. 2016. "Application of Remote Sensing and Gis in Agriculture and Natural Resource Management Under Changing Climatic Conditions." Agricultural Research Journal 53(3): 295.

Kogan, F, Sustainable Development, and Goals Series. 2019. "7.1 Introduction."

Kuželka, Karel, and Peter Surový. 2018. "Automatic Detection and Quantification of Wild Game Crop Damage Using an Unmanned Aerial Vehicle (UAV) Equipped with an Optical Sensor Payload: A Case Study in Wheat." European Journal of Remote Sensing 51(1): 241-50. https://doi.org/10.1080/22797254.2017.1419 442.

Lee, W. et al. 2010. "Sensing Technologies for Precision Specialty Crop Production." Computer and Electronic in Agriculture 74: 2-33.

Lu, D., and Q. Weng. 2007. "A Review of Picture Arrangement Strategies and Procedures for Improving Grouping Execution.” International Journal of Remote Sensing 28(5): 823-870.

M. Chi, Q. Kun, J. A. Benediktsson, and R. Feng. 2009. "Troupe Order Calculation for Hyperspectral Remote Detecting Information." IEEE Geosci. Remote Sensing Letters 6(4): 762- 766.

Mirik, Mustafa et al. 2013. "Remote Monitoring of Wheat Streak Mosaic Progression Using SubPixel Classification of Landsat 5 TM Imagery for Site Specific Disease Management in Winter Wheat." Advances in Remote Sensing. 2: 16-28.

Nock, Charles A, Richard J Vogt, and Beatrix E Beisner. 2016. "Functional Traits." eLS: 1-8.

Qu, J. S., S. B. Qu, and Z. J. Wang. 2009. "Highlight Based Fluffy Neural System Approach for Target Arrangement and Acknowledgment in Remote Detecting Pictures." Journal of Remote Sensing 13(1):
$68-74$.

Riedell, W. E., S. L. Osborne, and L. S. Hesler. 2004. "Insect Pest and Disease Detection Using Remote Sensing Techniques." In Proceedings of 7th International Conference on Precision Agriculture. Minneapolis, MN USA.,.

Tarbalka, Y., M. Fauvel, J. Channusot, and J.Benediktsson. 2010. "SVM and MRF Based Technique for Precise Grouping of Hyperspectral Pictures." IEEE Geo Science Remote detecting Lett. 3(7): 736-40.

Thenkabail, P. S. et al. 2013. "Selection of Hyperspectral Narrowbands (HNBs) and Composition of Hyperspectral Twoband Vegetation Indices (HVIs) for Biophysical Characterization and Discrimination of Crop Types Using Field Reflectance and Hyperion/EO-1 Data." IEEE Journal of Selected Topics in Applied Earth Observations and Remote Sensing. 6(2): 427-39.

Thenkabail, P. S., G. J. Lyon, and A. Huete. 2011. Advances in Hyper Spectral Remote Sensing of Vegetation and Agricultural Crops.

Whitcraft, Alyssa K., Inbal Becker-Reshef, Brian D. Killough, and Christopher O. Justice. 2015. "Meeting Earth Observation Requirements for Global Agricultural Monitoring: An Evaluation of the Revisit Capabilities of Current and Planned Moderate Resolution Optical Earth Observing Missions." Remote Sensing 7(2): 1482-1503.

Zhang, Jixian. 2010. "Multi-Source Remote Sensing Data Fusion: Status and Trends." International Journal of Image and Data Fusion 1(1): 5-24. 